\title{
ELETROCOAGULAÇÃO-FLOTAÇÃO APLICADA AO TRATAMENTO DE EFLUENTES GERADOS NA INDÚSTRIA DE RECICLAGEM DE PLÁSTICOS
}

\section{ELETROCOAGULATION-FLOTATION APPLIED TO THE TREATMENT OF WASTEWATER GERATED IN PLASTIC RECYCLING INDUSTRY}

\section{Izabela Major Barbosa ${ }^{1}$; Francisco Javier Cuba Teran ${ }^{2}$}

\author{
${ }^{1}$ Universidade Estadual de Campinas - izamajor@yahoo.com.br \\ ${ }^{2}$ Universidade Estadual Paulista Júlio de Mesquita Filho - fteran@fct.unesp.br
}

\section{RESUMO}

Uma alternativa para disposição da crescente quantidade de resíduos plásticos produzida pela população tem sido a reciclagem mecânica dos mesmos exigindo lavagem das embalagens a serem recicladas. $\mathrm{O}$ efluente produzido é reutilizado no próprio processo industrial. O presente estudo traz a Eletro-Coagulação-Flotação (ECF) como forma de tratamento de efluente de reciclagem de plásticos. $\mathrm{O}$ tratamento é baseado na eletrólise, coagulação e flotação com produção in situ de coagulante. Neste estudo foi utilizado um sistema em escala piloto, no qual ocorreu a coagulação química, a partir da passagem de corrente elétrica por eletrodos de alumínio seguida da formação de flocos de impurezas, os quais foram separados da fase líquida por flotação devido à formação de microbolhas de hidrogênio, geradas na eletrólise da água. A eficiência do tratamento foi verificada em termos de remoção de Demanda Química de Oxigênio-DQO, nitrogênio amoniacal e turbidez alcançando valores de $80 \%, 80 \%$ e $90 \%$ respectivamente. Também houve desinfecção, sendo esta uma característica favorável adicional do processo. Os fatores responsáveis pelo desempenho estão relacionados ao tempo de detenção do efluente sob passagem de corrente, à distância entre os eletrodos, ao pH e a intensidade da corrente elétrica. Palavras-chave: Reciclagem. Coagulação. Eletrólise. Flotação. Desinfecção.

\section{ABSTRACT}

An alternative for final disposal of the growing amount of plastic residues produced by the population has been their mechanical recycling witch demands washing plastic foils prior to industrial process. The produced wastewater is reused in 
the same industrial process. The present study presents Eletro-coagulation-Flotação (ECF) as a form of treatment of effluents of recycling of plastics, the treatment is based on the electrolysis, coagulation and flotation with coagulant production in situ. This study used a pilot scale system in which chemical coagulation take place, starting from the passage of electric current for aluminum electrodes followed by sludge flakes formation. These solids were separated from the liquid phase by flotation due to the formation of micro bubbles of hydrogen, generated in the electrolysis of the water. The efficiency of the treatment was verified in terms of removal of Chemical Oxygen Demand (COD), ammonia nitrogen and turbidity, values obtained were of $80 \%, 80 \%$ and $90 \%$ respectively. There was also disinfection, being this an additional favorable characteristic of the process. The responsible factors for the efficiency were related to under current effluent hydraulic detention time, distance between the electrodes, $\mathrm{pH}$ and intensity of the electric current.

Keywords: Recycling. Coagulation. Electrolysis. Flotation. Disinfection.

\section{INTRODUÇÃO}

Segundo o Instituto Brasileiro de Geografia e Estatística - IBGE (2000), estima-se que sejam gerados no país, por volta de 162 mil toneladas de resíduos sólidos ao dia. A pesquisa Ciclosoft, realizada em 327 municípios brasileiros, indica que $17,4 \%$ do lixo urbano coletado são representados por plásticos de todos os tipos em São Paulo/SP. Cerca de 19,0\% dos plásticos rígidos e filme foram reciclados no Brasil em 2006, e retornaram à produção na forma de matéria-prima, o que equivale aproximadamente a 200 mil toneladas por ano. Deste total, segundo a organização Compromisso Empresarial para Reciclagem 40\% provêm do lixo urbano. (CEMPRE, 2008).

Com a crescente produção de resíduos sólidos plásticos, a reciclagem é uma alternativa para reduzir o volume de resíduos. As etapas que constituem a reciclagem mecânica de plásticos pós-consumo são: moagem, lavagem, secagem, extrusão e granulação (ZANIN e MANCINI, 2004).

A lavagem, etapa responsável pela produção de efluente, separa os plásticos de outros materiais, como areia, papéis, outros plásticos, terra e matéria-orgânica. A lavagem ocorre normalmente em tanques com tamanhos variáveis.

A água que passa pelo sistema de tratamento existente na indústria retorna ao processo produtivo em circuito fechado e a quantidade de materiais em suspensão oriunda da lavagem dos plásticos é responsável pela tonalidade do material a ser produzido, ou seja, não há adição de corantes. Existe uma classificação para as tonalidades: cristal, mesclado, colorido, canela e preto.

Para fins de maior sustentabilidade, é recomendada a reutilização da água utilizada na lavagem de plásticos, para tal sugere-se o uso da Eletro-Coagualção- 
Flotação - ECF para tratar este efluente, uma vez que o uso de produtos químicos em sistemas que empregam tratamento físico-químico com coagulação, floculação e decantação, requer elevadas dosagens que aumentam o custo do funcionamento e pode não remover alguns poluentes de maneira satisfatória.

As principais vantagens da Eletro-Coagulação-Flotação estão relacionados com o tamanho da célula eletrolítica, com os reduzidos tempos de detenção, com a menor produção de lodo e com a não necessidade de equipamentos de dosagem (WIENDL, 1998).

Diante dessa explanação, surge como alternativa para tratar efluentes industriais o uso dos métodos eletroquímicos baseados na oxidação e redução catódica de eletrodos metálicos, neste caso em alumínio. Nesse processo, o elétron é o principal reagente, evitando o uso de outros compostos químicos.

O tratamento por eletrólise ocorre na presença de dois eletrodos submersos em uma solução contendo eletrólitos, com uma tensão aplicada. A passagem de corrente elétrica é responsável pelas reações que ocorrem no meio: a oxidação de compostos e a substituição iônica entre os eletrólitos inorgânicos e os sais orgânicos, com a conseqüente redução da concentração da matéria orgânica dissolvida na solução e a desestabilização das partículas coloidais por eletrocoagulação (GIORDANO, 2003).

Após a floculação, as microbolhas do gás hidrogênio produzidas no cátodo juntam-se aos coágulos, propiciando a flotação dos resíduos em suspensão que formam o lodo do processo. A eletroflotação é favorecida também pelas menores distâncias entre os eletrodos, devido ao movimento ascensional do gás hidrogênio. A coagulação é obtida pela introdução de íons coagulantes produzidos pelo desgaste do eletrodo denominado ânodo, neste caso, $\mathrm{Al}^{3+}$ (GIORDANO, 2003; CRESPILHO e REZENDE, 2004).

Segundo Chen (2004), o "sal de cozinha" é usualmente empregado para o aumento da condutividade da água residuária a ser tratada. A adição de cloreto de sódio $(\mathrm{NaCl})$ leva também à diminuição do consumo de energia devido ao aumento da condutividade, além disso, o cloro gerado eletroquimicamente é eficiente na desinfecção do efluente tratado. Estudos realizados com tratamento por eletrólise de efluentes de indústrias alimentícias comprovam a desinfecção dos despejos. Esta redução de microorganismos deve-se à presença de cloretos. (HERNLEM, 2000).

Outra vantagem verificada no processo de (ECF) é a possibilidade de remoção de amônia do efluente por "stripping" que tem como princípio a remoção física por arraste, ou seja, sem adição de produtos químicos. A amônia existente em águas residuárias de lavagem dos plásticos, provavelmente é oriunda da decomposição, em meio anaeróbio, de proteínas e de outros compostos nitrogenados presentes nos resíduos sólidos urbanos (GIORDANO, 2003).

Sendo assim, a ECF pode ampliar as alternativas para tratamento de efluentes oferecendo baixo custo em relação aos processos convencionais, áreas reduzidas de implantação, reduzidos custos com obras, facilidade de operação, alta remoção para 
diversas substâncias danosas ao processo de reciclagem de plásticos e, somada a todas as outras, proporciona desinfecção dos líquidos tratados.

\section{MATERIAIS E MÉTODOS}

O sistema objeto deste estudo estava composto por eletrodos de alumínio, reator de Eletro-Coagulação-Flotação $(E C F)$ e fonte para alimentação de corrente contínua.

O conjunto de eletrodos em alumínio era formado por 6 placas planas com espessura inicial de $5 \mathrm{~mm}$ e dimensões de $10 \mathrm{~cm} \times 15 \mathrm{~cm}$, sendo 2 de alimentação (chamados de placas condutoras) e 4 de sacrifício, mantidas em posições paralelas entre si e sem interconexão elétrica, de forma que cada eletrodo tenha polaridade diferente de seus vizinhos. O espaçamento entre os eletrodos foi definido em $5 \mathrm{~mm}$, pois segundo Crespilho (2004) essa distância não permite o contato elétrico entre as partes metálicas prevenindo curto-circuito e ainda potencializa a velocidade de ascensão das microbolhas de hidrogênio. À distância entre os eletrodos foi mantida fixando-os em três tubos de PVC.

O reator de ECF possuía capacidade para tratar um volume de até 10 litros de águas residuárias, tendo diâmetro de $14,5 \mathrm{~cm}$ e altura igual a $41 \mathrm{~cm}$, foi construído em acrílico transparente de modo a possibilitar a visualização de seu interior. No corpo do reator existiam orifícios para possibilitar a retirada do líquido tratado livre de material em flotação e/ou em sedimentação.

A fonte de alimentação de corrente elétrica utilizada para este experimento tinha amperagem máxima de $10 \mathrm{~A}$ e tensão máxima de $15 \mathrm{~V}$.

Seguindo a sugestão de Crespilho (2004), a corrente aplicada foi fixada em 4 A e a tensão registrada na fonte de alimentação para esta corrente elétrica foi de $13 \mathrm{~V}$. O reator de ECF em funcionamento e a fonte de alimentação de corrente contínua podem ser observados na Figura 1.

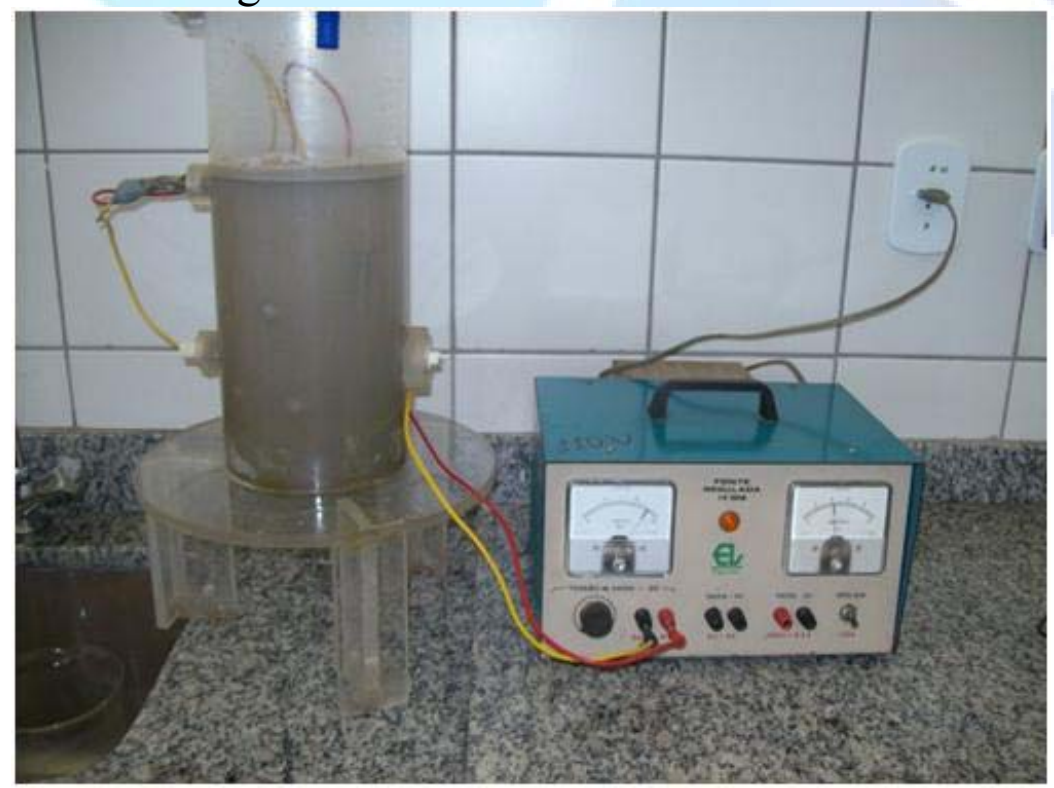

Figura 1. Reator de ECF, em funcionamento, e fonte de alimentação 
O funcionamento da indústria de reciclagem de plásticos é ininterrupto com recirculação da água de segunda a sexta-feira. A água utilizada para lavagem dos plásticos é descartada após cerca de 50 horas de uso, desse modo, optou-se por realizar o monitoramento de amostras a cada 10 horas de uso para lavagem de plásticos. Assim as amostras foram coletadas depois de 10, 20, 30, 40 e 50 horas de funcionamento durante duas semanas.

Por existir um tratamento preliminar para os despejos líquidos da indústria composto por gradeamento, caixa de areia e decantador primário, as amostras coletadas para serem tratadas por ECF foram denominadas como Pré-tratado e após passar pelo reator de ECF, como Tratado.

Os valores verificados para condutividade do efluente em questão mostraramse baixos, por isso foi necessário que a condutividade fosse elevada através da adição de $3 \mathrm{~g} / \mathrm{L}$ de cloreto de sódio. Com a condutividade estabelecida em cerca de 4 $\mathrm{mS} / \mathrm{cm}$, a corrente elétrica verificada na fonte de alimentação de corrente contínua foi de $4 \mathrm{~A}$. A tensão aplicada foi de $13 \mathrm{~V}$, conforme o registrado na fonte de alimentação de corrente contínua.

O volume tratado por ECF em cada batelada foi de 4 litros. O tempo de detenção do líquido sob passagem de corrente elétrica variou entre 4 e 7 minutos. $\mathrm{O}$ período de repouso para flotação total dos agregados formados durante a ECF foi de uma hora. A passagem de corrente era interrompida quando a espuma flotada tomava coloração esbranquiçada, indicando que a remoção de sólidos havia cessado. $\mathrm{O}$ período aguardado para flotação total dos flocos foi necessário para a obtenção de um efluente tratado livre de materiais que ainda pudessem estar em processo de flotação.

$\mathrm{Na}$ primeira semana realizou-se monitoramento com ajuste de condutividade apenas, e na semana seguinte, o $\mathrm{pH}$ também foi ajustado de maneira a ficar na faixa entre 7 e 8 com adição de hidróxido de sódio ao $50 \%$.

Foram estudados os seguintes parâmetros: Turbidez, $\mathrm{pH}$, condutividade, DQO, sólidos totais, sólidos fixos, sólidos voláteis, nitrogênio amoniacal e o potencial de desinfecção.

Os métodos aplicados foram baseados no Standard Methods for the examination of water and wastewater (APHA, 1998).

Para verificar a remoção dos poluentes em questão foram avaliados, em todas as amostras os teores antes e depois do tratamento por ECF.

A avaliação qualitativa da desinfecção após o tratamento por ECF foi feita por meio do cultivo de microorganismos existentes nas amostras em meio nutriente à base de ágar. A metodologia para o meio nutriente foi adaptada aos produtos existentes no laboratório da Faculdade de Ciências e Tecnologia, Unesp, Campus Presidente Prudente em que se deu o estudo. Para o uso do meio produzido houve assepsia do mesmo, através de autoclavagem a $120^{\circ} \mathrm{C}$ durante 15 minutos.

Foram preparadas quatro placas de petri para cada batelada, sendo duas destinadas à inoculação do líquido antes de passar pelo tratamento por ECF e as outras duas após o tratamento por ECF. 
A inoculação dos microorganismos no meio de cultura foi feita com aplicação de $0,5 \mathrm{ml}$ do despejo retirado da indústria e $0,5 \mathrm{ml}$ de efluente tratado por ECF nas devidas placas de petri previamente identificadas. O período de incubação foi estabelecido em 24 horas em estufa a $24^{\circ} \mathrm{C}$ de temperatura para todas as amostras avaliadas.

Para avaliar o potencial de desinfecção da ECF, a bancada, o reator e toda a vidraria utilizada, foram lavados com álcool $70 \%$. Todas as inoculações foram realizadas na proximidade do fogo, reduzindo assim a possibilidade de contaminação das amostras por microorganismos externos ao sistema.

\section{RESULTADOS E DISCUSSÃO}

\subsection{Resultados da Primeira Semana de Monitoramento}

\section{Aparência}

As amostras de efluente coletadas na indústria de reciclagem após períodos 10, $20,30,40$ e 50 horas de uso para lavagem dos plásticos podem ser observadas na Figura 2. É válido ressaltar que a amostra correspondente ao tempo de lavagem de 50 horas corresponde à coloração "canela" do material reciclado, sendo este o líquido considerado com maior índice de poluentes devido ao maior tempo de uso para lavagem dos plásticos.

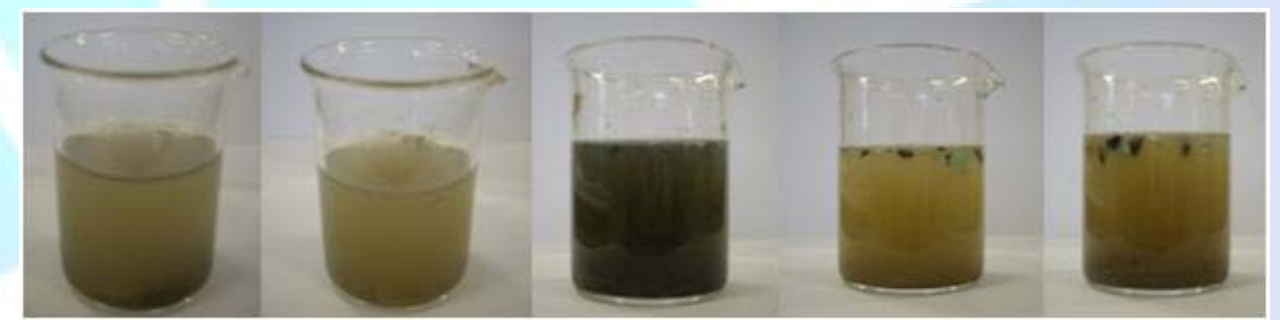

Figura 2. Amostras de efluente de 10, 20, 30, 40 e 50 horas de funcionamento da indústria

As amostras coletadas depois de 10,20,30,40 e 50 horas de funcionamento da indústria foram tratadas por ECF e podem ser visualizadas na Figura 3.

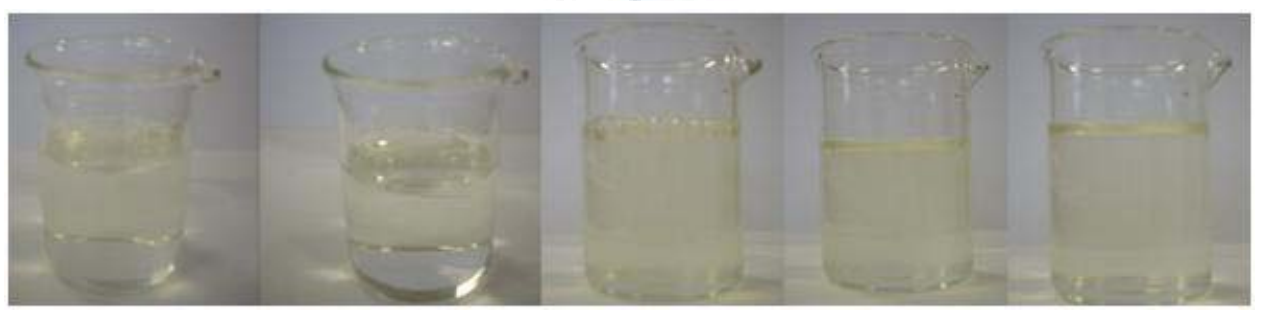

Figura 3. Efluentes de 10, 20, 30, 40 e 50 horas tratados por ECF 
Visualmente é possível identificar que houve remoção de material em suspensão com o uso de ECF para tratar estes efluentes oriundos da reciclagem de plásticos.

\section{Variação da Turbidez}

Na Figura 4 tem-se o gráfico das variações de turbidez verificadas nas amostras antes e após o tratamento por ECF.

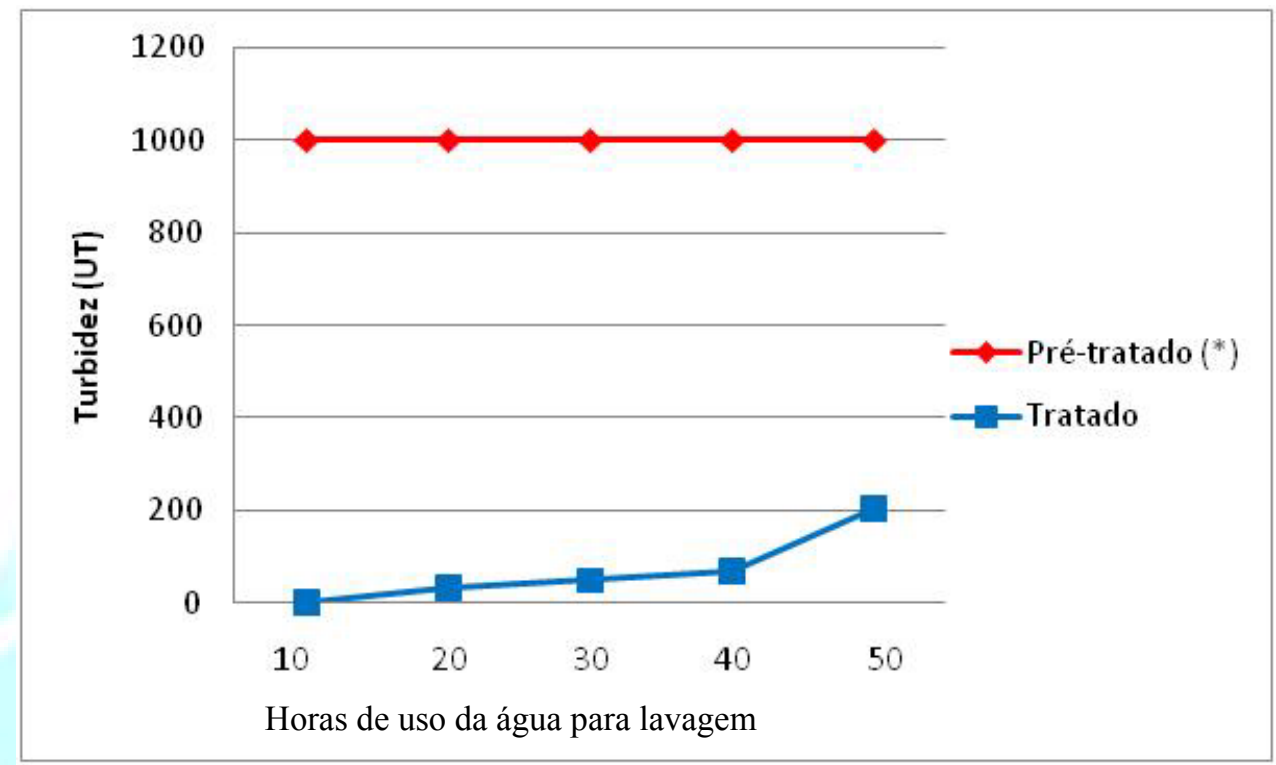

Figura 4. Variações para turbidez

(*) limite máximo de detecção do equipamento.

Segundo informações da indústria, a quantidade de sólidos em suspensão existente na água utilizada para a lavagem dos plásticos está diretamente relacionada à coloração que o produto reciclado terá, ou seja, uma água mais turva na lavagem dos plásticos resulta em grânulos mais escuros. Estes grânulos possuem menor valor de venda se comparados com os grânulos transparentes provenientes da lavagem da matéria prima com água clarificada (10 primeiras horas de uso de água para lavagem).

Foi possível verificar reduções significativas para a turbidez após a ECF de até 99\% devido a flotação dos sólidos em suspensão, conforme mostra a Tabela 1.

Tabela 1 - Redução de turbidez com uso de ECF

\begin{tabular}{cc}
\hline Horas & Eficiência de Remoção \\
\hline 10 & 99 \\
20 & 97 \\
30 & 95 \\
40 & 93 \\
50 & 80 \\
\hline
\end{tabular}




\section{Variações de $\mathrm{pH}$}

$\mathrm{O} \mathrm{pH}$ é um dos fatores primordiais para que ocorra a ECF, pois se relaciona com a solubilidade de gases responsáveis pela flotação, assim está diretamente relacionado à eficiência no tratamento. Na Figura 5 está o gráfico com os valores de $\mathrm{pH}$ verificados nas amostras de 10, 20, 30, 40 e 50 horas de lavagem de plásticos antes e após a ECF.

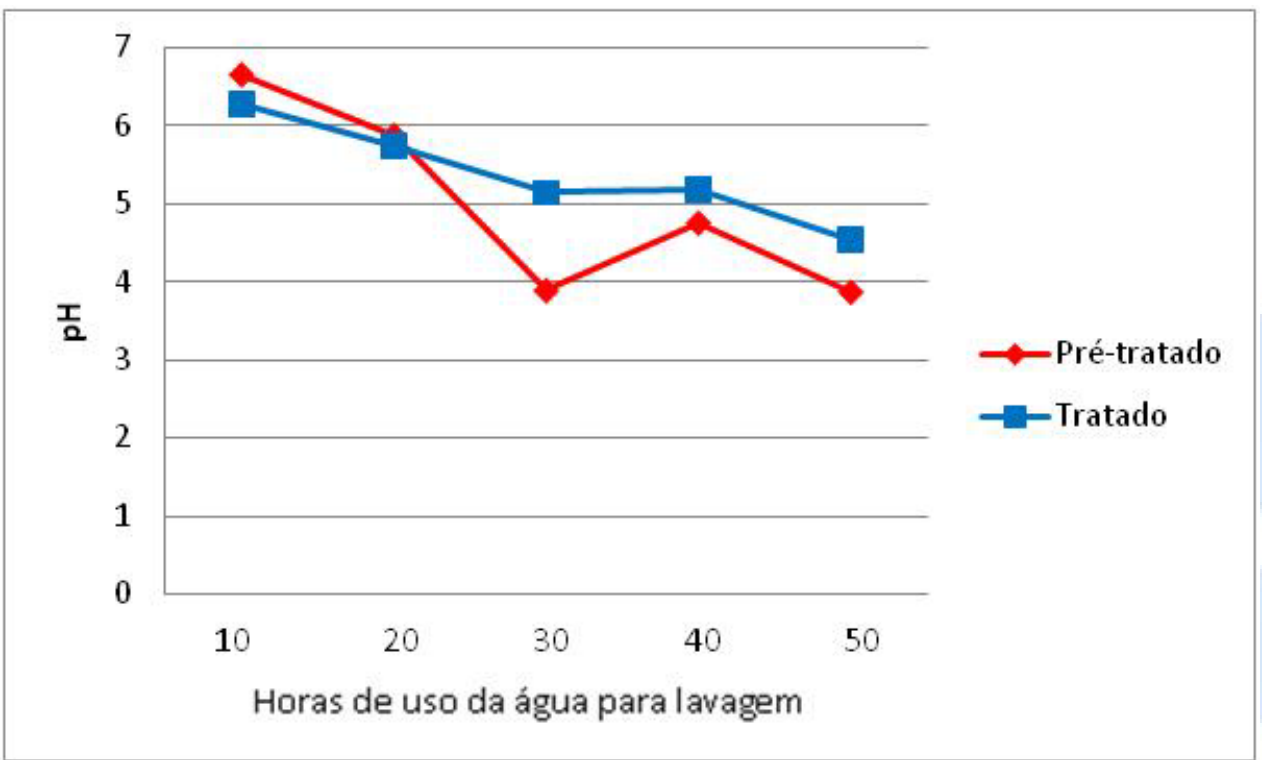

Figura 5. Gráfico dos valores de $\mathrm{pH}$ das amostras antes e após o tratamento por ECF

Variação da Demanda Química de Oxigênio (DQO)

Através da DQO verificada é possível estimar a quantidade de matéria orgânica existente no efluente e removida com a eletrólise.

Na Figura 6 é possível observar o gráfico com os valores de DQO verificados nas amostras antes e depois do tratamento por ECF.

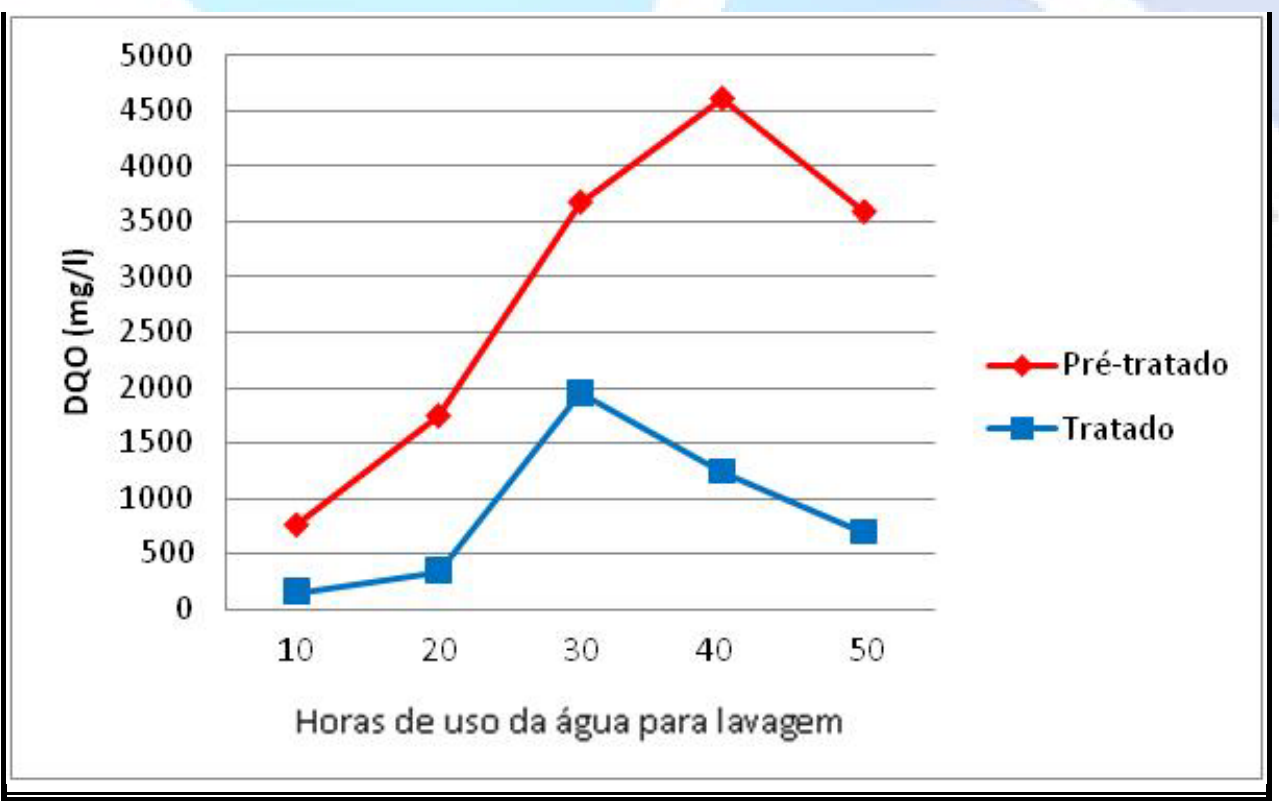

Figura 6. Gráfico dos valores de DQO para amostras antes e após a ECF 
A Tabela 2 mostra as eficiências de remoção atingidas com o uso da ECF para as amostras de 10, 20, 30, 40 e 50 horas de uso.

Tabela 2 - Eficiência de Remoção de QDO com a ECF

\begin{tabular}{cc}
\hline Horas & Eficiência de Remoção \\
\hline 10 & $80 \%$ \\
20 & $80 \%$ \\
30 & $47 \%$ \\
40 & $73 \%$ \\
50 & $81 \%$ \\
\hline
\end{tabular}

As eficiências de remoção de DQO foram satisfatórias sendo na maioria delas superior a $70 \%$, com exceção do valor correspondente a 30 horas em que pode ter ocorrido erro experimental.

\section{Variação de Sólidos Totais, Sólidos Fixos e Sólidos Voláteis}

Os valores observados para sólidos dizem respeito apenas à parcela líquida dos efluentes coletados, não sendo neste estudo analisada a espuma gerada pelo sistema.

Os sólidos totais abrangem a existência de matéria orgânica e inorgânica nos líquidos analisados. O gráfico para variação dos valores de sólidos totais verificados nas amostras antes e após o tratamento por ECF encontra-se na Figura 7.

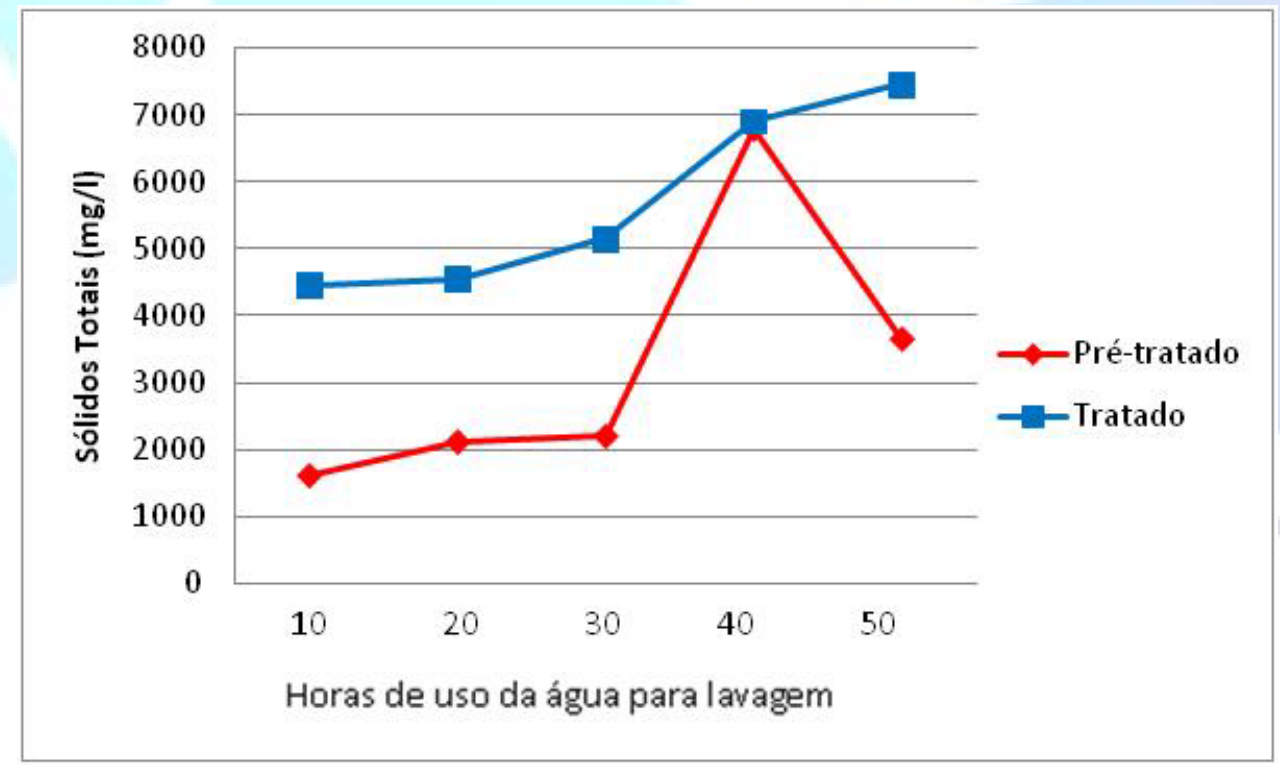

Figura 7. Variação de sólidos totais nas amostras antes e após a ECF

Como é possível observar, houve aumento da concentração de sólidos totais para quase todas as amostras tratadas por ECF. Este fato pode ser atribuído à produção de hidróxidos durante a ECF, assim como à presença dos compostos adicionados para acondicionar o líquido pré-tratado ao processo físico-químico. 
Os sólidos fixos retratam a existência de materiais inorgânicos existentes no meio. A Figura 8 mostra o gráfico das variações de sólidos fixos para as amostras de efluentes industriais e tratadas por ECF.

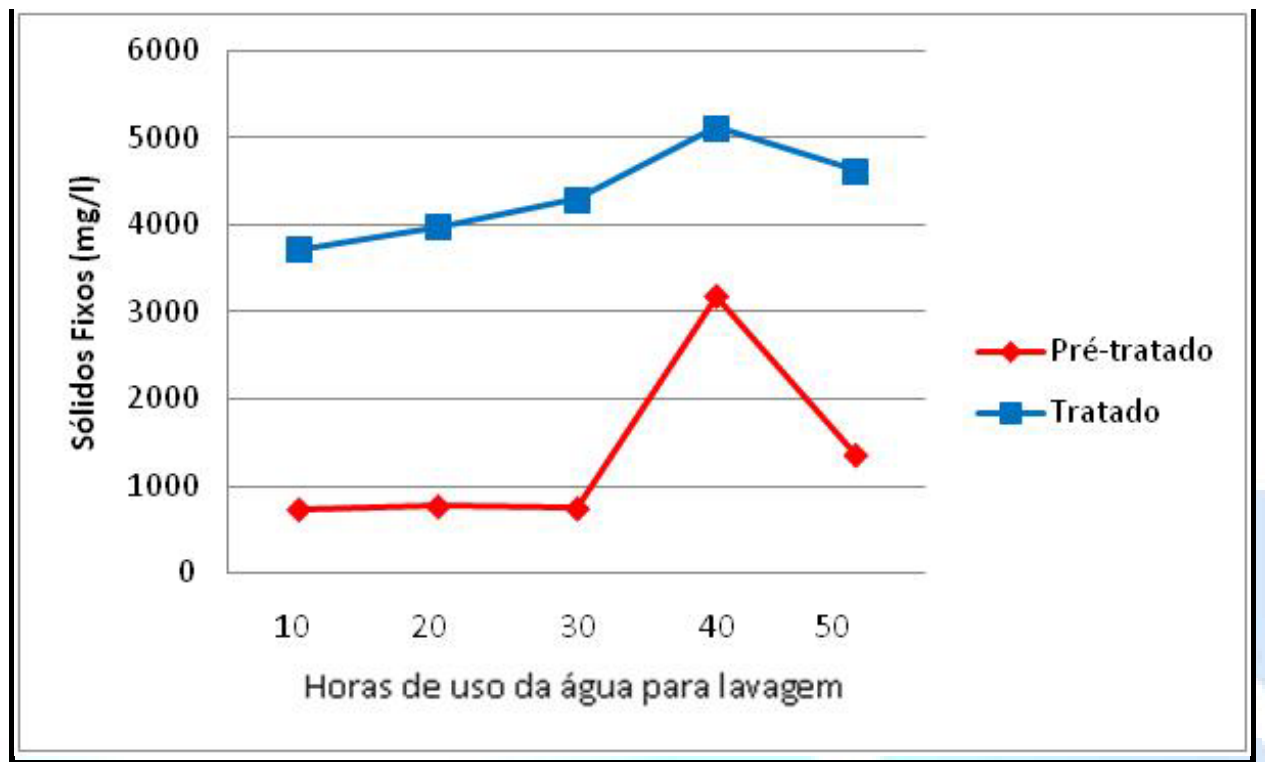

Figura 8. Variações verificadas para Sólidos Fixos nas amostras antes e após a ECF

Após análise do gráfico com os valores de sólidos fixos das amostras foi possível verificar que houve aumento de sólidos fixos, confirmando, então o aumento observado para sólidos totais. Acredita-se que este aumento se deva à formação de hidróxido de alumínio durante a ECF. Esse comportamento também pode ser atribuído à presença dos compostos adicionados para acondicionar o líquido prétratado ao processo físico-químico.

A remoção de matéria orgânica é coerente com os valores encontrados para sólidos voláteis, indicando índices inferiores para as amostras tratadas por ECF, como pode ser observado na Figura 9 com o gráfico das variações para sólidos voláteis.

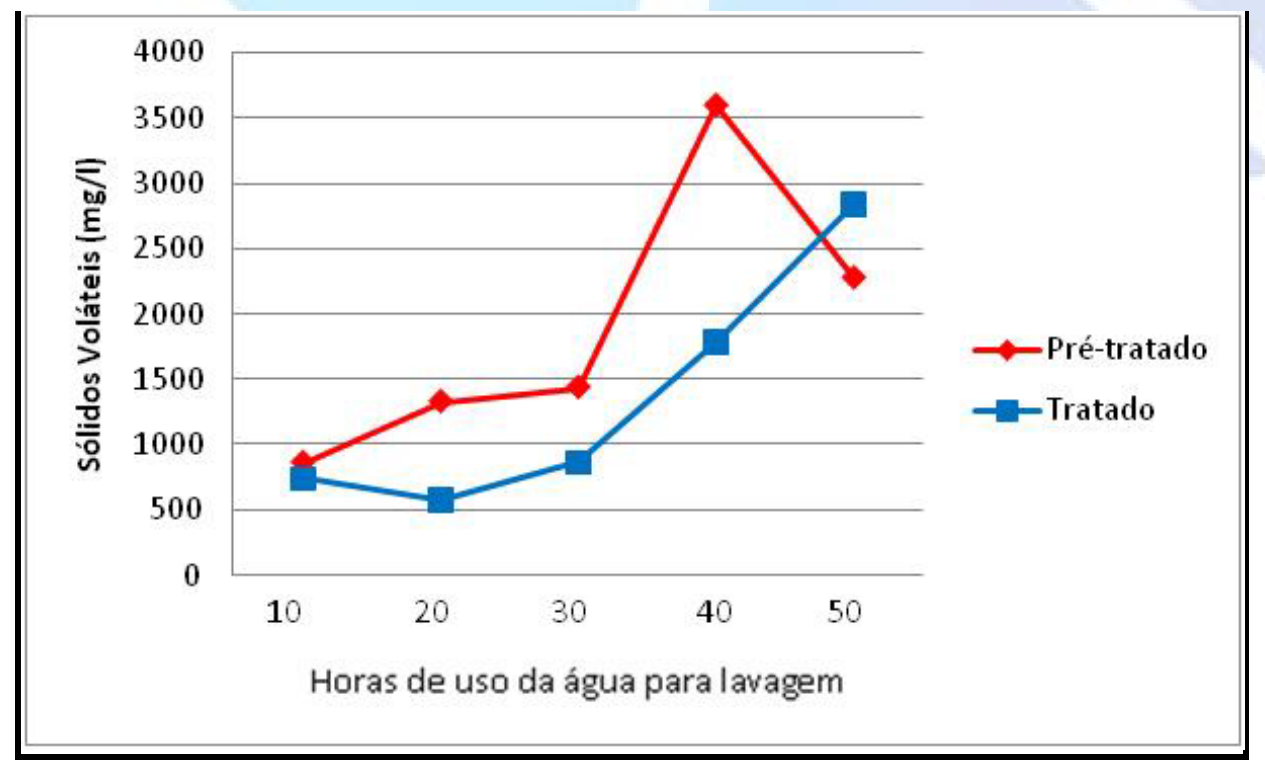

Figura 9. Variações de Sólidos Voláteis para as amostras antes e após ECF 


\section{Remoção de Nitrogênio Amoniacal por ECF}

A amônia que possa existir em águas residuárias de lavagem de plásticos pósconsumo é, provavelmente, advinda da decomposição, em meio anaeróbio, de proteínas e de outros compostos nitrogenados presentes nos Resíduos Sólidos Urbanos.

Acredita-se que além da reação com o cloro, o "stripping" possa ter favorecido a remoção de nitrogênio amoniacal durante a ECF, sendo viabilizado sem adição de ar, uma vez que o desprendimento do gás hidrogênio forma microbolhas, as quais fariam com que o $\mathrm{N}$-amoniacal fosse removido por desprendimento da fase líquida, devido ao seu baixo peso molecular.

Os valores de nitrogênio amoniacal para as amostras de efluente antes e após a ECF podem ser analisados no gráfico existente na Figura 10.

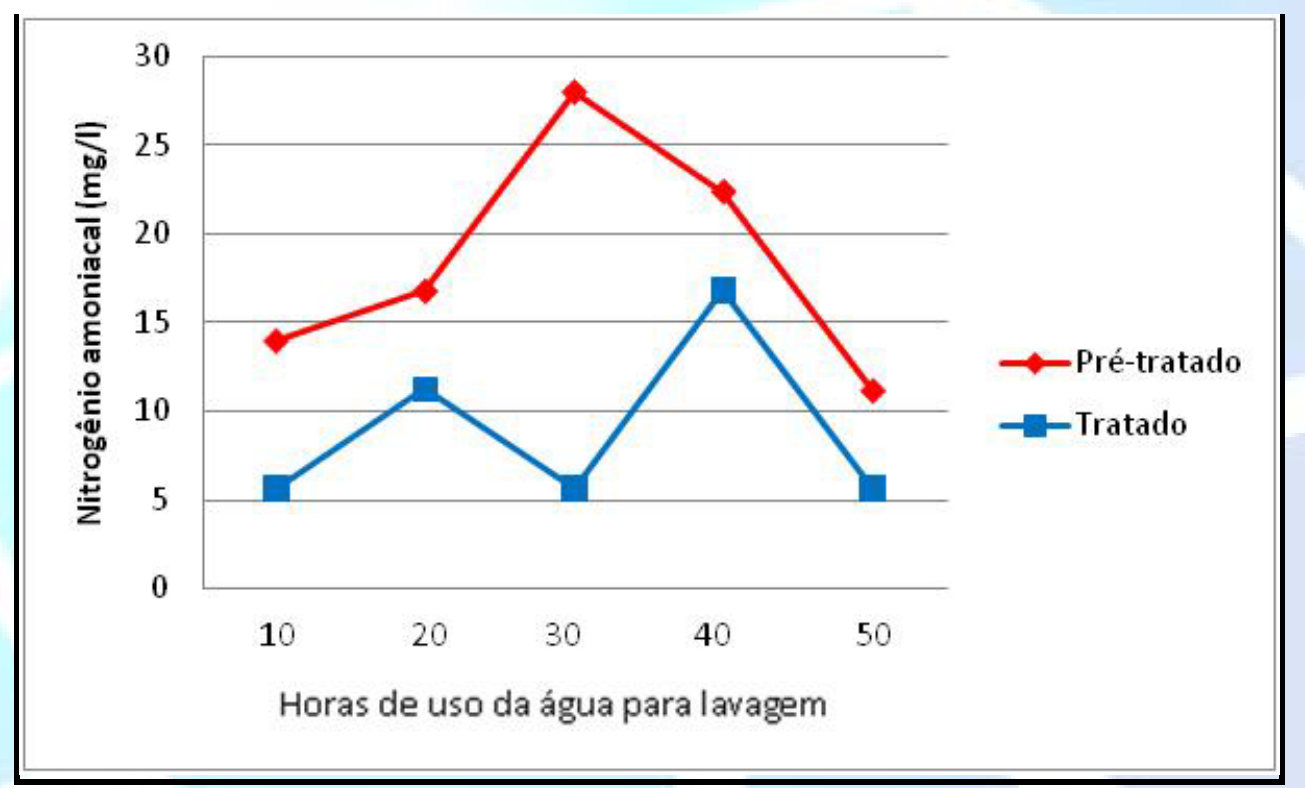

Figura 10. Variações para Nitrogênio Amoniacal nas amostras antes e após a ECF

Dessa forma, encerrou-se a primeira semana de monitoramento das amostras de efluentes gerados após de 10,20,30,40 e 50 horas de lavagem de plásticos e das análises realizadas nas mesmas amostras após o tratamento por Eletro-CoagulaçãoFlotação.

\subsection{Resultados da Segunda Semana de Monitoramento (com ajuste do $\mathrm{pH}$ )}

Chen (2004) afirma ainda, que as melhores remoções de poluentes encontramse na faixa de $\mathrm{pH}$ neutro para eletrodos do alumínio. Os efluentes coletados na indústria de reciclagem de plásticos possuem pH baixo, na faixa entre 3 e 6 , dessa forma houve intervenção de modo a elevar o $\mathrm{pH}$ com adição de produtos químicos com o intuito de elevar a eficiência do tratamento por ECF.

Testes foram feitos com cal hidratada (solução a 10\%), mas não houve êxito devido a que o cálcio atribuiu ao tratado coloração esbranquiçada; pois, segundo 
Russel (1994), os íons $\mathrm{Ca}^{2+}$ podem ser precipitados como carbonatos brancos de soluções básicas, talvez por este motivo a coloração apresentada no despejo após eletrólise contendo cal tenha sido esta tonalidade, portanto optou-se pelo uso de hidróxido de sódio.

Os parâmetros avaliados nesta segunda semana de análises com $\mathrm{pH}$ elevado foram: $\mathrm{pH}$, Condutividade; DQO, sólidos totais, sólidos fixos, sólidos voláteis, nitrogênio amoniacal e, qualitativamente, a potencialidade de desinfecção da ECF. O parâmetro turbidez não pode ser verificado devido a falhas nos equipamentos.

As amostras de efluentes foram coletadas após 10, 20,30, 40 e 50 horas de funcionamento da indústria de reciclagem e podem ser visualizadas na Figura 11. Após a coleta das amostras e adição de hidróxido de sódio até que a faixa de $\mathrm{pH}$ entre 7 e 8 fosse atingida, o despejo foi tratado no reato de ECF.
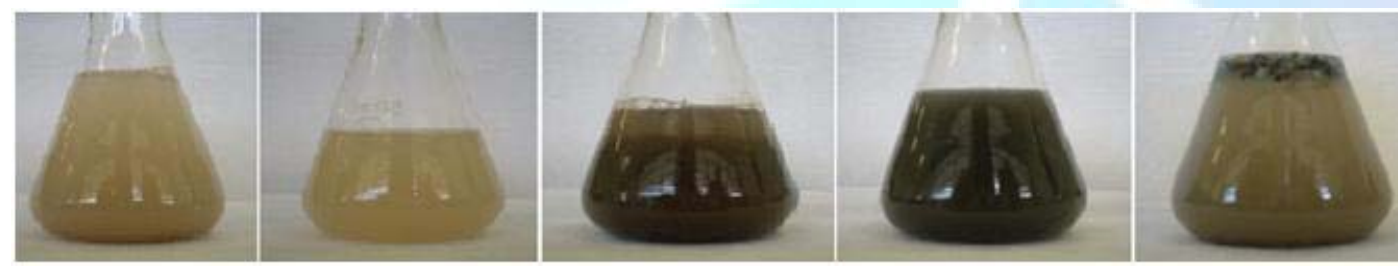

Figura 11. Amostras de efluentes coletados após 10, 20, 30, 40 e 50 horas de lavagem de plásticos

As amostras após o tratamento por ECF podem ser observadas na Figura 12.

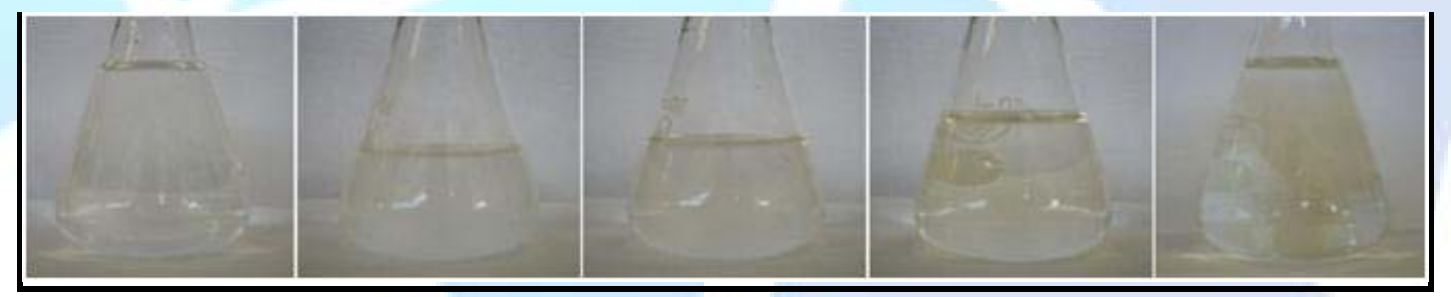

Figura 12. Amostras de 10, 20, 30, 40 e 50 horas de lavagem de plásticos tratadas por ECF

\section{Variação de $\mathrm{pH}$}

A Figura 13 mostra o gráfico com os valores de $\mathrm{pH}$ para as amostras das coletadas na indústria, para o $\mathrm{pH}$ ajustado e para as amostras tratadas. 


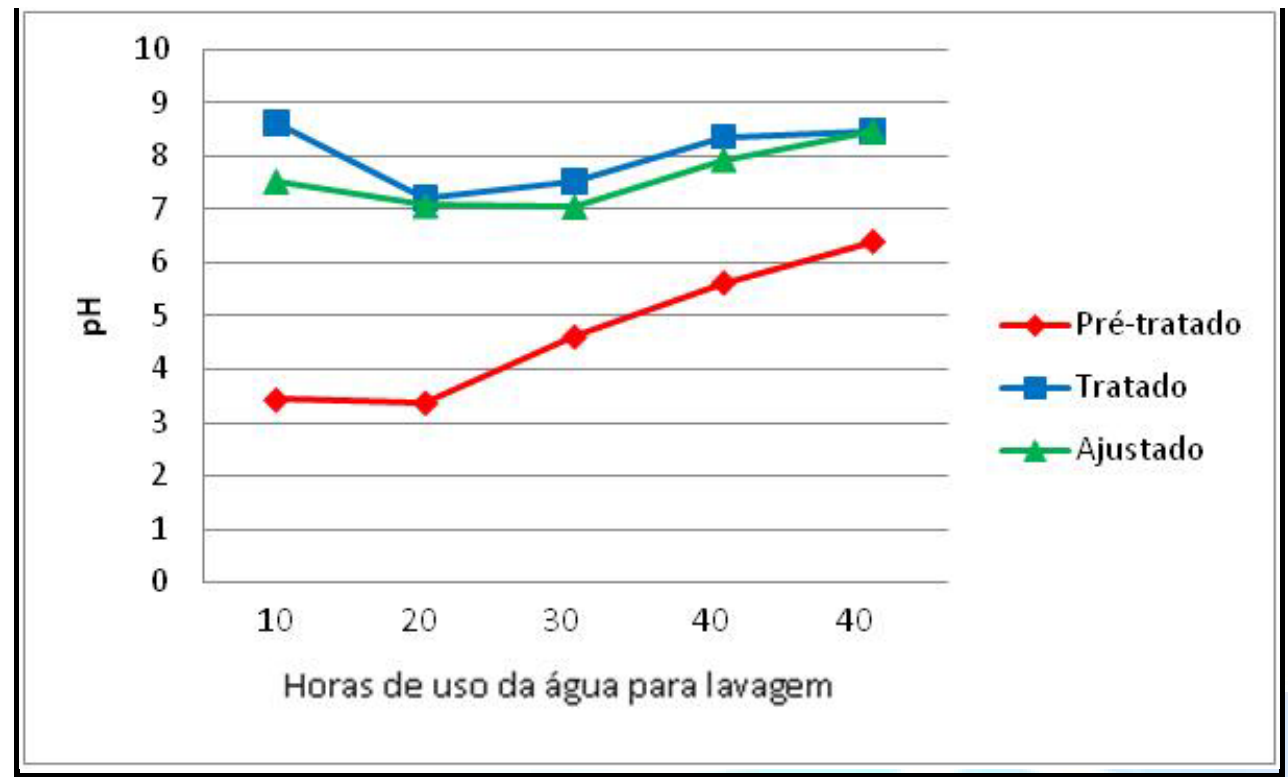

Figura 13. Variações de pH para as amostras sem adição de $\mathrm{NaOH}$, com adição de $\mathrm{NaOH}$ e após a $\mathrm{ECF}$

Ao analisar o gráfico acima é possível notar que mesmo após o ajuste de $\mathrm{pH}$ houve um discreto aumento no $\mathrm{pH}$ das amostras após tratamento com eletrólise além do valor ajustado.

\section{Variação da Demanda Química de Oxigênio (QDO)}

A DQO foi também observada para as amostras com $\mathrm{pH}$ ajustado, os valores verificados encontram-se no gráfico da Figura 14.

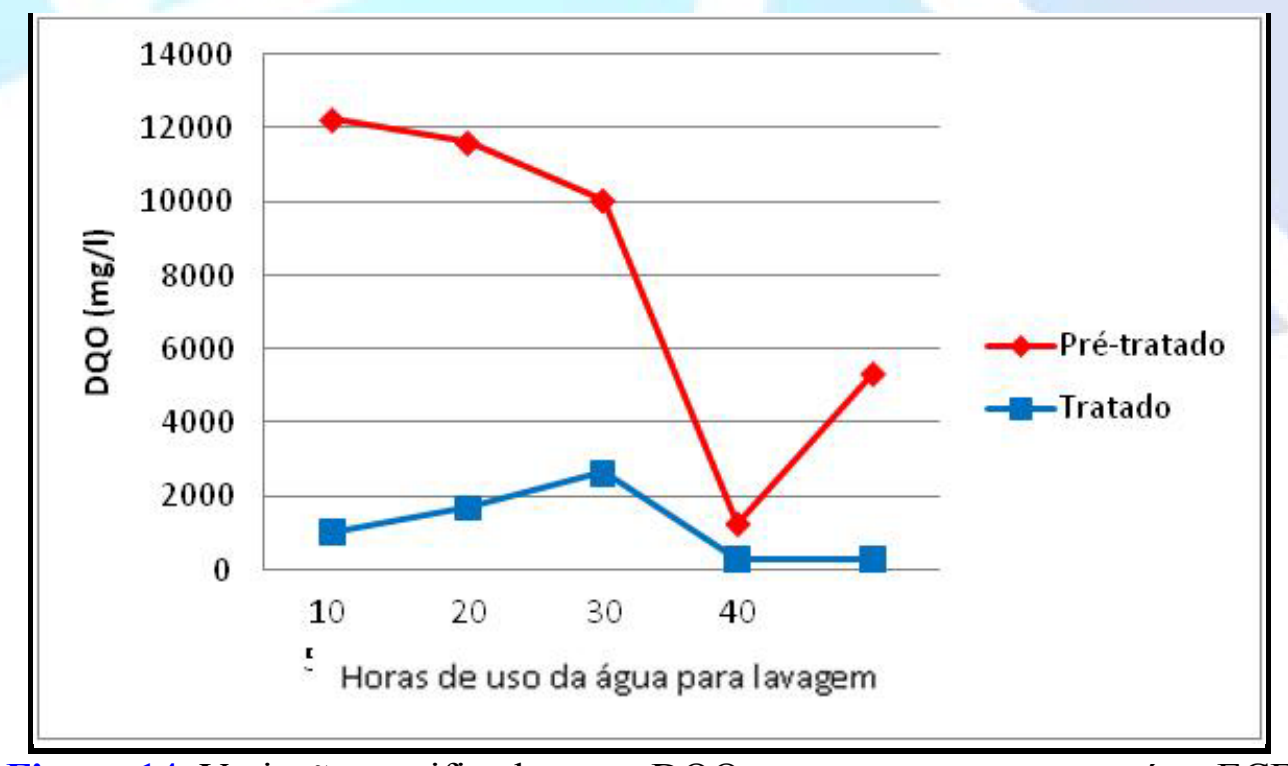

Figura 14. Variações verificadas para DQO nas amostras antes e após a ECF 
Variações comuns na qualidade do despejo bruto produzido no processo industrial podem ter ocasionado o fato de o despejo líquido utilizado por maior período para lavagem dos plásticos possuir valores de DQO inferiores aos valores das amostras de efluente de menor tempo de uso.

\section{Variação dos Sólidos Totais, Sólidos Fixos e Sólidos Voláteis}

Nas amostras com adição de hidróxido de sódio foram observados os índices de sólidos totais para as amostras de 10, 20,30, 40 e 50 horas de funcionamento da indústria de reciclagem de plásticos sem intervenção para elevar o $\mathrm{pH}$ e após $\mathrm{o}$ tratamento por ECF. O gráfico com os valores verificados encontra-se na Figura 15.

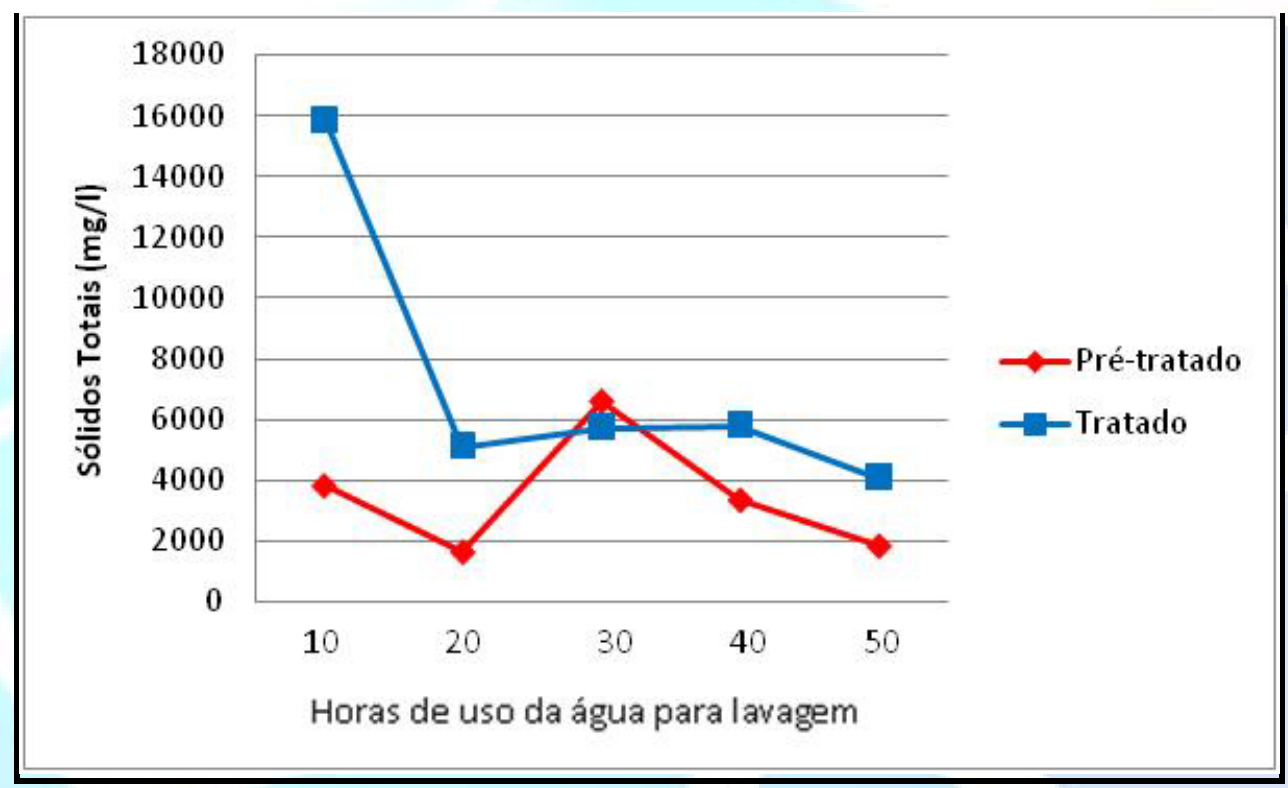

Figura 15. Variações verificadas para Sólidos Totais nas amostras antes e após a ECF

Nos valores apresentados no gráfico é possível notar aumento de sólidos totais após o tratamento por ECF, que conforme discutido anteriormente, deve-se à formação de hidróxidos de alumínio e à presença de outros sais adicionados.

A análise de sólidos fixos confirma este fato com o aumento dos valores verificados em todas as amostras tratadas por ECF. O gráfico apresentado na Figura 16 apresenta os valores de sólidos fixos para as amostras coletadas na indústria e após a ECF. 


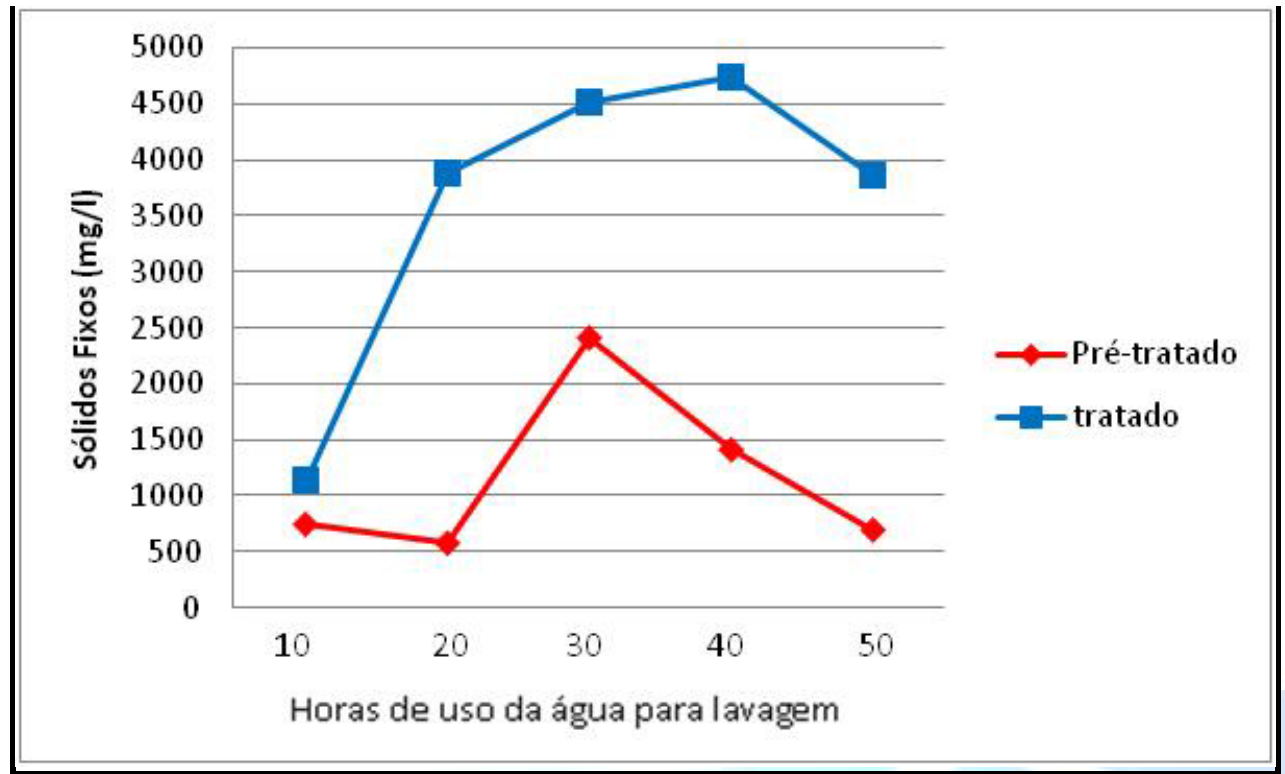

Figura 16. Variações para Sólidos Fixos nas amostras antes e após a ECF

A partir da análise de sólidos voláteis foi possível verificar redução para as amostras após o tratamento por ECF, conforme pode ser observado no gráfico existente na Figura 17.

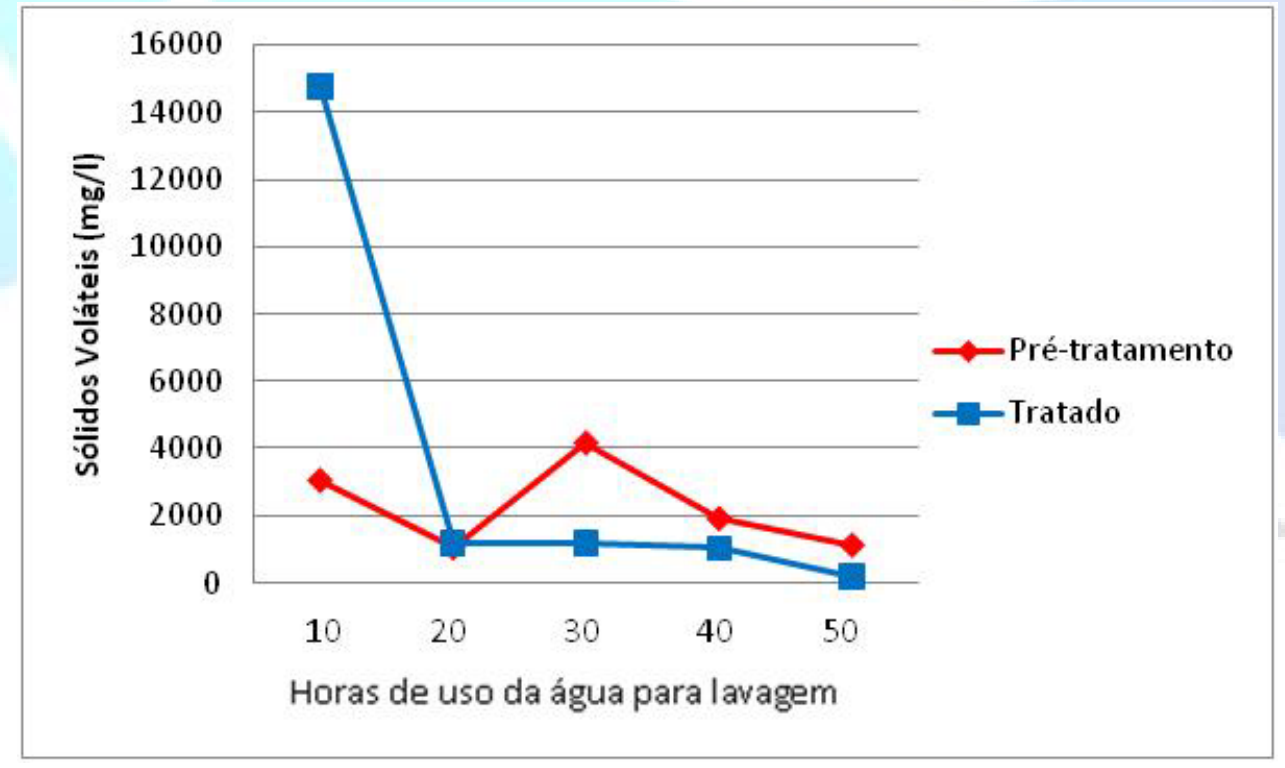

Figura 17. Variações para Sólidos Voláteis nas amostras antes e após a ECF

Os valores verificados no gráfico mostram-se contraditórios, pois não indicam que tenha ocorrido redução na matéria orgânica existente no despejo. 


\section{Remoção de Nitrogênio Amoniacal por ECF}

A remoção de nitrogênio amoniacal foi também verificada para as amostras com o pH ajustado. A remoção observada para estas amostras foi satisfatória e os valores para nitrogênio amoniacal encontram-se no gráfico apresentado na Figura 18.

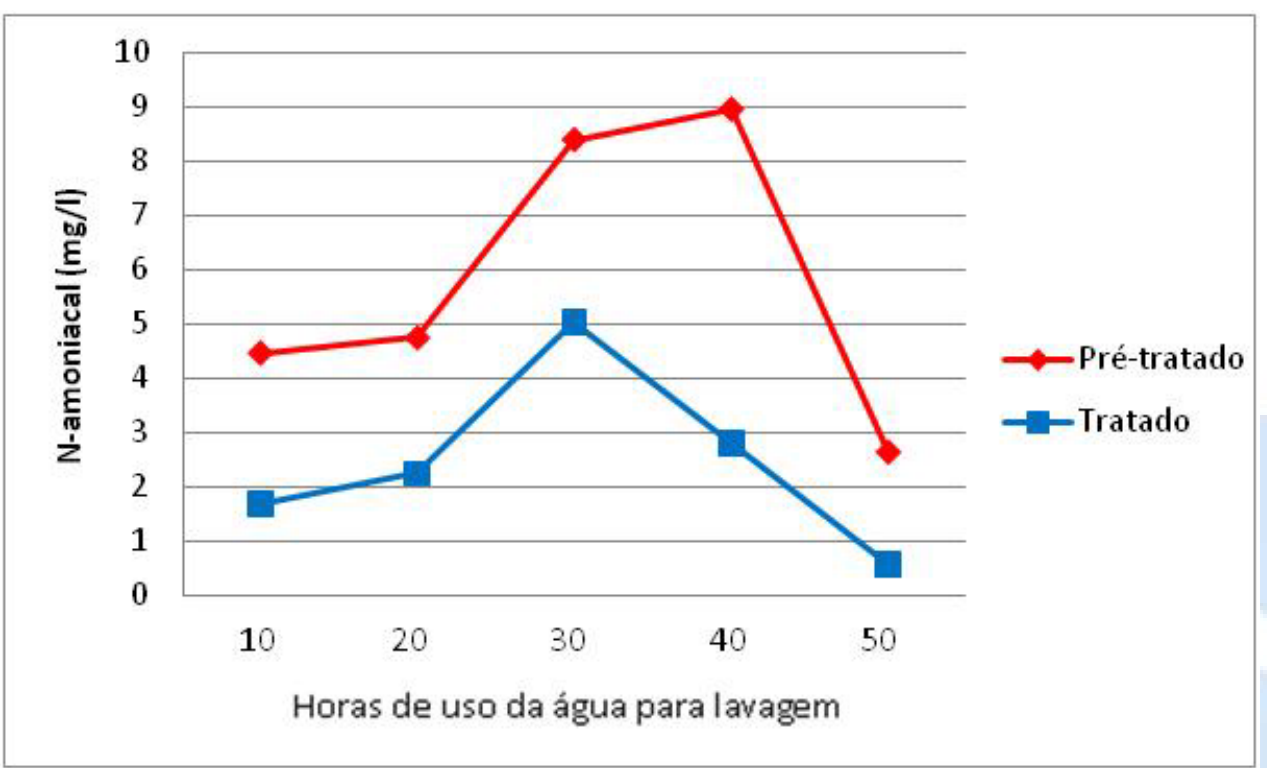

Figura 18. Variações para Nitrogênio Amoniacal nas amostras entes e após a ECF

Na tabela 3 é possível observar os valores da eficiência de remoção de nitrogênio amoniacal para as amostras tratadas por ECF.

Tabela 3 - Eficiência de Remoção de nitrogênio amoniacal

\begin{tabular}{cc}
\hline Horas & Eficiência de remoção \\
\hline 10 & $63 \%$ \\
20 & $53 \%$ \\
30 & $40 \%$ \\
40 & $69 \%$ \\
50 & $79 \%$ \\
\hline
\end{tabular}

Assim, baseando-se nos estudos realizados por Giordano (2003) quanto à remoção de nitrogênio amoniacal, em tratamentos com uso de eletrólise e nos resultados obtidos para remoção de nitrogênio amoniacal, a ECF mostrou-se capaz de remover nitrogênio amoniacal do despejo líquido em estudo.

\section{Desinfecção com uso da ECF}

A adição de cloreto de sódio empregada para elevar a condutividade da água residuária a ser tratada, contribuindo ionicamente, pôde ainda resultar em formação de compostos com cloro capazes de promover desinfecção dos líquidos tratados. 
A desinfecção pode sim ocorrer quando se trata de processos eletrolíticos de acordo com relatos encontrados na literatura. Os resultados apresentados basearam-se apenas no aspecto visual da proliferação de microorganismos. Para observar o potencial de desinfecção da ECF as placas de petri contendo nutrientes e as amostras antes e após a ECF foram cultivadas para que o crescimento de microorganismos pudesse ser avaliado.

As placas podem ser visualizadas nas Figuras 19, 20, 21 e 22.

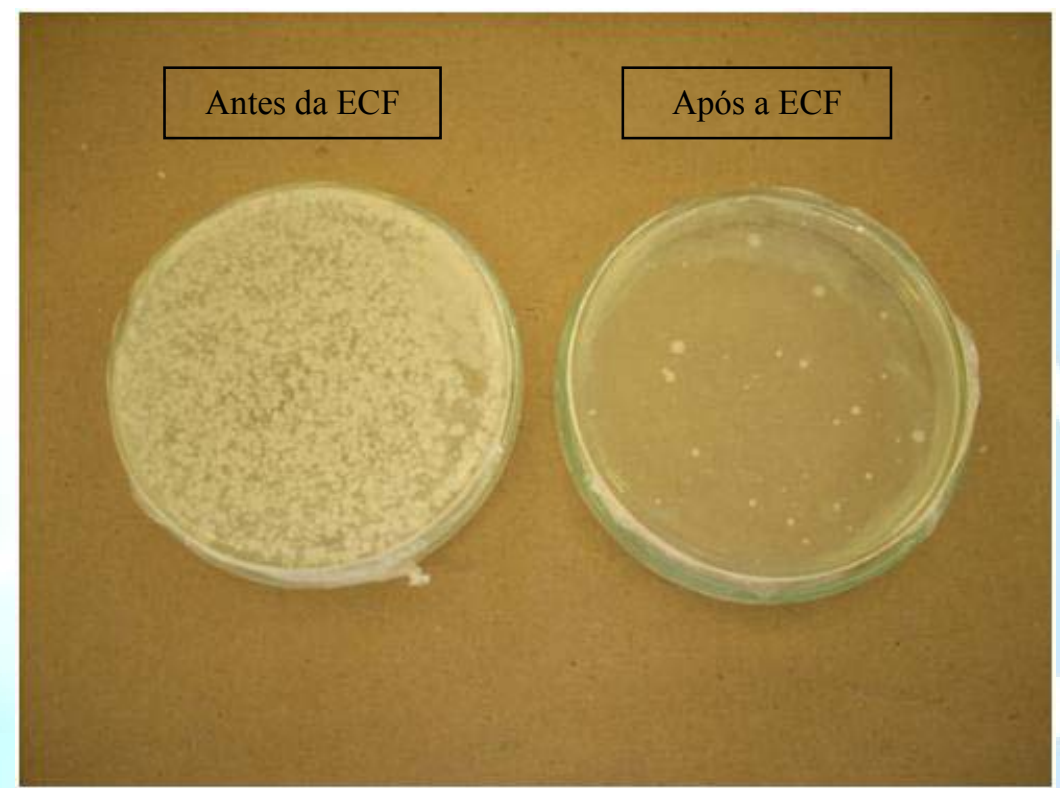

Figura 19. Cultivo de microorganismos de 10 horas de lavagem, antes e depois da ECF

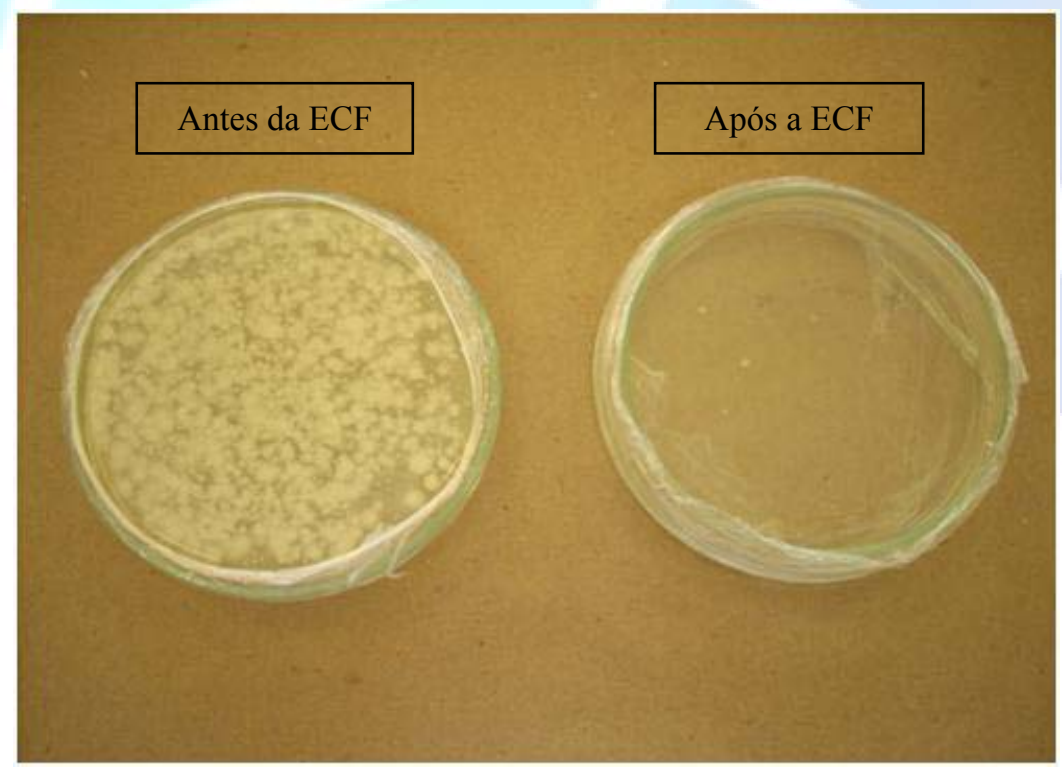

Figura 20. Cultivo de microorganismos de 20 horas de lavagem, antes e depois da ECF 


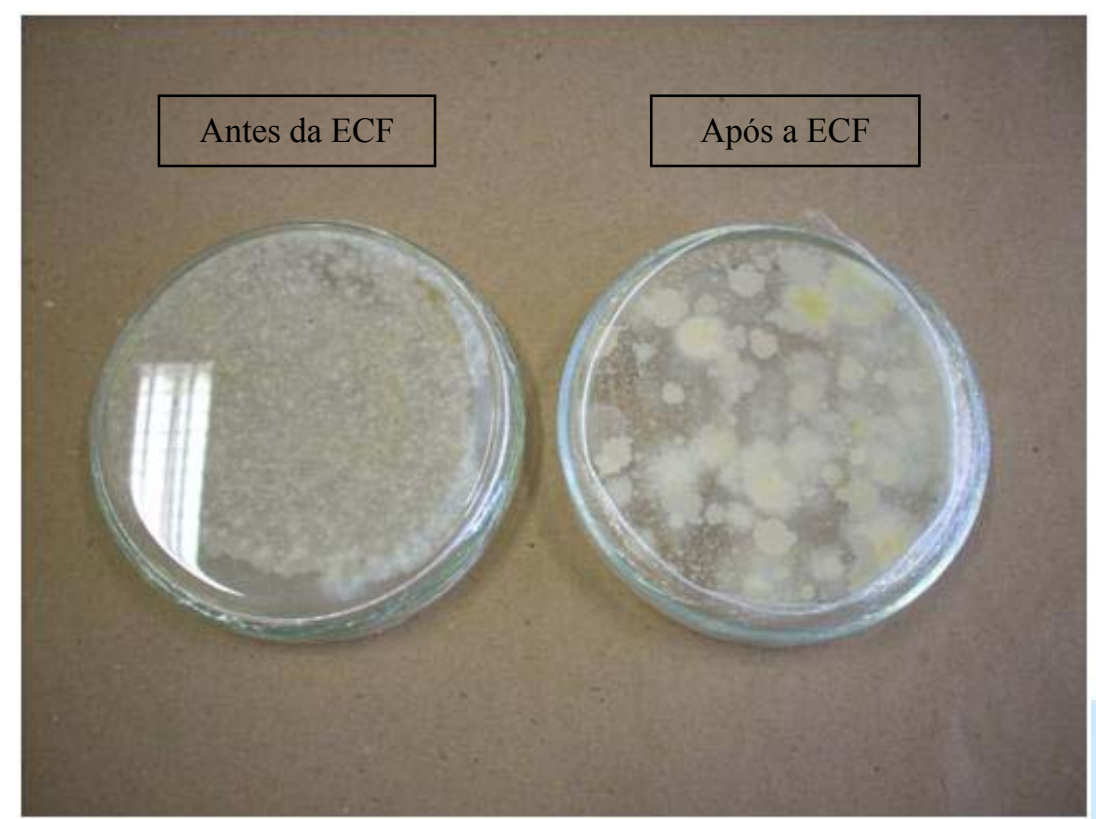

Figura 21. Cultivo de microorganismos de 30 horas de lavagem, antes e depois da ECF

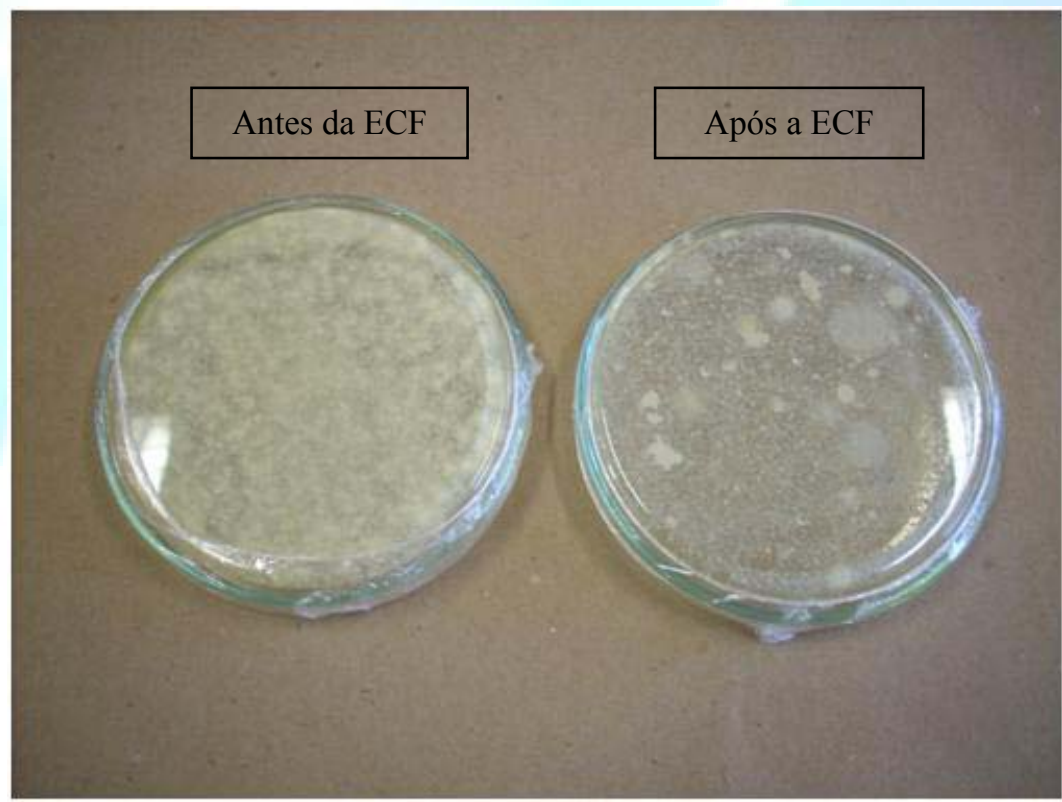

Figura 22. Cultivo de microorganismos de 40 horas de lavagem, antes e depois da ECF

As amostras de 50 horas de lavagem não foram avaliadas devido a problemas operacionais do laboratório.

Como foi possível observar houve redução na proliferação de microorganismos quando das amostras tratadas com ECF. Embora ainda houvesse desenvolvimento de colônias de bactérias em todas as placas destinadas às amostras tratadas por ECF e alguns fungos nas placas de 30 horas.

A eficiência reduzida nessas duas mostras pode ser decorrente da presença de microorganismos em maior quantidade e também a presença de sólidos no efluente 
tratado pode interferir no processo de desinfecção; pois, segundo Gonçalves (2003) estes podem proteger os microorganismos da ação desinfetante.

\section{CONCLUSÕES}

A partir dos resultados alcançados neste trabalho pode-se concluir que o tratamento por Eletro-Coagulação-Flotação mostra-se extremamente eficiente para a remoção de matéria orgânica em suspensão no líquido.

A EFC possui grande potencialidade de ser aplicada para conseguir elevada eficiência na desinfecção de águas residuárias contaminadas com microrganismos patogênicos.

A remoção de amônia pode ser obtida a partir do arraste da fase gasosa e a partir da reação com o cloro proveniente de eletro-oxidação do cloreto adicionado na forma de $\mathrm{NaCl}$ para aumentar a condutividade do meio.

A aplicação da ECF permite o reuso do efluente em um número maior de lavagens da matéria prima, sendo que produz um líquido com baixa turbidez, baixa concentração de matéria orgânica e tem a potencialidade de propiciar a desinfecção. Um efluente tratado com essa qualidade permitiria melhorar a qualidade do produto do processo industrial assim como diminuir seu custo.

\section{AGRADECIMENTOS}

Os autores agradecem o apoio do pessoal técnico da Faculdade de Ciências e Tecnologia da Universidade Júlio de Mesquita Filho assim como o financiamento da Fundação para o Desenvolvimento da UNESP - FUNDUNESP.

\section{REFERÊNCIAS}

APHA- AMERICAN PUBLIC HEALTH ASSOCIATION. Standard Methods for the Examination of Water and Wastewate. 20 ed.Washington: American Public Health Association, AWWA, WPCF, 1998. 1569p.

CEMPRE - Compromisso Empresarial para Reciclagem. Disponível em: $<$ http://www.cempre.org.br/fichas_tecnicas.>.Acesso em 18 de outubro de 2008.

CHEN, G. Electrochemical technologies in wastewater treatment. Separation and Purification Technology, v.157, n.1, p. 11- 41, julho. Hong Kong, China, Elsevier. 2004. 
CRESPILHO, F. N; REZENDE. M. O.O. Eletroflotação: Princípios e Aplicações. São Carlos: RIMA, 2004.

GIORDANO, G. Análise e formulação de processos para tratamento dos chorumes gerados em aterros sanitários de resíduos sólidos urbanos. 2003. $257 \mathrm{f}$. Tese (Doutorado em Ciência dos Materiais e Metalurgia) - Universidade Católica do Rio de Janeiro. 2003.

GONÇALVES, R. F. Desinfecção de efluentes sanitários. Rio de Janeiro: Rima, 2003. $438 \mathrm{p}$.

HERNLEM, B. J.; TSAI, L. S. Chlorine generation and desinfection by eletroflotation. Journal of Food Science. vol 65, n. 5, p. 834 - 837, 2000.

IBGE. INSTITUTO BRASILEIRO DE GEOGRAFIA E ESTATÍSTICA. Pesquisa Nacional de Saneamento Básico, Rio de Janeiro. 2000.

RUSSEL, J. B. Química Geral. Márcia Guekezian. 2a Ed.1994. Rio de Janeiro. vol. II. 892 p.

WIENDL, W. G. Processo eletrolítico no tratamento de esgotos sanitários. Rio de Janeiro: ABES. 1998. 368 p.

ZANIN, M., MANCINI, S., D. Resíduos plásticos e reciclagem: Aspectos Gerais e Tecnologia. 2004. São Carlos: Edufscar. 143 p.

Manuscrito recebido em: 04/02/2009 Revisado e Aceito em: 25/09/2009 